\title{
Correlates of quit intentions among current Nigerian smokers: Evidence from the 2012 Global Adult Tobacco Surveys (GATS)
}

\author{
Oluwatomi Iken', Eniola Cadmus², Bolaji Ahmed'
}

\begin{abstract}
INTRODUCTION Approximately 3.1 million people use tobacco in Nigeria contributing to the burden of tobacco-related morbidity and mortality. However, many tobacco users who have tried to quit have been unable to do so at the first try, but may succeed or give up after multiple attempts. The transtheoretical model helps by classifying those with quit intentions into preparation, contemplation and precontemplation stages. These assist in the development of targeted interventions towards smokers in each stage for more effective results. There is limited evidence about cessation and quitting behaviour in the Nigerian context. This study aimed to explore the factors related to the intention to quit among current tobacco smokers in Nigeria using the transtheoretical model.

METHODS The study was a secondary data analysis of the Nigeria 2012 Global Adult Tobacco Survey (GATS). The survey included non-institutionalized men and women aged $\geq 15$ years. Data were analysed using SPSS version 21 . The primary outcome variable was smoking quit intention. The correlates of quit intentions were determined for a $\mathrm{p}<0.05$.

RESULTS A total of 429 current smokers were mostly in precontemplation (64.7\%) while $14.9 \%$ were in the preparation stage. Exposure to anti-tobacco media messages was associated with increased quit attempts, however, knowledge about the harmful effects of tobacco was associated with fewer quit intentions. Very few had access to cessation therapy and none had accessed a quitline. Male respondents were 9 times more likely to have a quit intention compared to females $(\mathrm{OR}=9.615 ; 95 \%$ CI: $1.449-1.478)$. Respondents with primary education were nearly three times more likely to have quit intentions than those with tertiary education ( $\mathrm{OR}=2.991 ; 95 \%$ CI: $2.930-3.053)$.

CONCLUSIONS While attention is on smoking prevention, most smokers in Nigeria are not considering quitting. There is a need for targeted interventions to reach smokers at various stages.
\end{abstract}

\section{AFFILIATION \\ 1 Department of Community Medicine, University College Hospital, Ibadan, Nigeria 2 Department of Community Medicine, College of Medicine, University of Ibadan, Ibadan, Nigeria}

\section{CORRESPONDENCE TO}

Oluwatomi Iken. Department of Community Medicine, University College Hospital, Ibadan, Nigeria. E-mail: ikenoluwatomi@gmail.com

\section{KEYWORDS}

Nigeria, smokers, quit intention, transtheoretical model

Received: 15 October 2019 Revised: 23 November 2019 Accepted: 9 December 2019

\section{INTRODUCTION}

Worldwide, tobacco use remains one of the most important causes of morbidity and premature death ${ }^{1}$. According to the World Health Organization (WHO), about $30 \%$ of the world's total population uses tobacco in some form ${ }^{1}$. Also, tobacco smoking contributes to six out of the eight leading causes of mortality worldwide $^{1}$. Although the consequences of tobacco smoking on health are slow and gradual, tobacco smoking remains an important risk factor for coronary artery disease, cerebrovascular disease, chronic obstructive pulmonary disease (COPD) and cancers of various organs such as lungs, larynx, oesophagus, oral cavity, and pharynx ${ }^{2}$. Moreover, smokers tend 
to experience greater productivity losses and suffer greater levels of impairment than non-smokers ${ }^{3}$.

While cigarette consumption continues to decline in high-income countries (HICs), its use is rising in low- and middle-income countries (LMICs) ${ }^{4}$. This has been attributed to the tobacco industry deliberately targeting LMICs due to their potential as newly emerging markets ${ }^{4,5}$. The increasing global burden of tobacco has necessitated several concerted efforts to control its use ${ }^{4}$. The World Health Assembly, therefore, approved the WHO Framework Convention on Tobacco Control (WHO/FCTC) in $2003^{1}$, formulated to ensure a global partnership to mitigate a global tobacco epidemic using evidencebased best practices for tobacco control ${ }^{1}$. Expectedly, one of the important aspects of tobacco control is smoking cessation. Although, few smokers are able to quit smoking spontaneously, due to the addictive nature of nicotine ${ }^{4}$, tobacco cessation services are reported to increase the number of smokers who wish to, and eventually, quit smoking ${ }^{6}$. These quit intentions usually precede quit attempts, which may eventually be successful or otherwise.

In many countries in Africa, tobacco control is often not seen as a health priority due to competing demands for other pressing health problems ${ }^{7}$. Furthermore, the interference of the tobacco industry and related economic gains (taxes and employment opportunities) have hampered tobacco control; hence, tobacco cessation services are rarely available at the population level in many developing countries. Though studies have assessed quit intentions and attempts, determinants of quit attempts, and eventually tobacco cessation, these have been studied among sub-populations such as adolescents, undergraduates or patients ${ }^{8-16}$. Studies that have assessed quit intentions and attempts, in the general population, have mostly been in HICs ${ }^{17-21}$. The WHO advises that, in order to effectively reduce tobacco-related morbidity and mortality by 2030 , combined prevention and cessation programs will achieve more than either intervention alone ${ }^{22}$. Although well documented in many HICs, there is limited evidence about cessation determinants and quit intentions in LMICs such as Nigeria. Furthermore, despite established benefits of application of behavioural theories to effect behavioural change, there has been no application of the transtheoretical model (TTM) to explore quit intentions in LMICs including Nigeria. This study, therefore, intends to describe the correlates of quit intentions among smokers in Nigeria using existing data.

\section{METHODS}

\section{Study population and study design}

The study was an analysis of secondary data from the 2012 Global Adult Tobacco Survey (GATS). The Global Adult Tobacco Survey (GATS) is part of the Global Tobacco Surveillance System (GTSS) developed by CDC (Centre for Disease Control) to provide global standards that systematically monitor tobacco use among individuals aged $\geq 15$ years. Randomly selecting one individual per household, a total of 9765 individuals were interviewed. The overall response rate for GATS Nigeria was $89.1 \%$. The household response rate was $90.3 \%(86.8 \%$ urban, $94.1 \%$ rural), while the individual response rate was $98.6 \%$ (98.0\% urban, $99.2 \%$ rural). Data were collected on sociodemographic characteristics, household possessions, smoking history and quit intention history, and other variables.

\section{Data analysis}

Data for current smokers were extracted and analysed using Statistical Package for Social Sciences version 21 (SPSS). Descriptive statistics were done using means, proportions, tables and charts. Bivariate analysis was done to determine factors associated with smoking quit attempts, and the level of statistical significance was set at $5 \%$. Binary logistic regression analysis was used to determine independent predictors of smoking quit attempts.

\section{Quit intention stage}

Based on the TTM theory, this was reported in three categories using responses to the question: 'Which of the following best describes your thinking about quitting smoking?'. A 'yes' response to 'I am thinking of quitting within the next one month' was defined as 'preparation stage'. A 'yes' response to 'I am thinking of quitting after one month but within the next 12 months' was defined as 'contemplation stage', while a 'yes' response to 'I am thinking of quitting someday but not in the next 12 months' was defined as 'precontemplation stage'. 


\section{RESULTS}

The mean age of respondents was $39.3( \pm 13.0)$ years. In addition, the respondents were distributed across the geopolitical zones of the country with the highest proportion from the Southwest (19.1\%) and least from the Northeast (11.2\%). Well over half of the respondents $(71.8 \%)$ resided in rural areas, and the majority $(95.4 \%)$ of the smokers were males. Over two-thirds $(63.9 \%)$ were literate, about $8.9 \%$ of the respondents were unemployed, and $22.5 \%$ belonged to the highest quintile of wealth. Furthermore, $40.6 \%$ of the respondents had quit intentions in the 12 months preceding the survey. However, respondents who had tried to quit smoking were able to sustain the behavioural change for different durations. The mean duration of quit attempts was three months ( \pm 10 days). The most prevalent reasons for quit intentions were health concerns $(31.0 \%)$ and family pressure $(24.9 \%)$. Other reasons for quit intentions were harm to others (20.3\%), disapproval by friends $(13.1 \%)$, cost $(8.9 \%)$, and their jobs $(4.4 \%)$. Only $14.7 \%$ of the respondents who had quit intentions had some form of support. Those who used nicotine gum or patch accounted for $2.7 \%$, while $3.7 \%$ used other prescription medication. In addition, $5.4 \%$ of those who had support used herbal/traditional medicines, while $10.0 \%$ used smokeless tobacco. None of the respondents had been able to access a quitline (none was available at the time of data collection). Moreover, about $27.0 \%$ of respondents had visited a doctor or healthcare worker in the past 12 months for general health complaints. During the visits, $66.4 \%$ were asked if they smoked and $90.9 \%$ had been advised to quit smoking by the healthcare provider. Furthermore, in the 30 days preceding the survey, $56.4 \%$ of respondents had noticed health warnings on cigarette packs and $40.5 \%$ of these had started thinking about quitting smoking. Most respondents (64.8\%) were in precontemplation stage, with $20.3 \%$ in contemplation stage, and $14.9 \%$ in preparation stage. Across the geopolitical zones in Nigeria, there were varying numbers of smokers in the three quit-stages as previously defined. Smokers with the highest level of education constituted a high proportion $(80.7 \%)$ of those in precontemplation stage. Furthermore, smokers who had the highest level of education had the lowest percentage of smokers $(2.6 \%)$ in the preparation stage. Smokers who were government employees were mostly in the preparation stage $(14.4 \%)$ while fewer smokers working in the private sector were in the preparation stage (34.5\%).

Furthermore, a smoker who was likely to make quit attempts was likely to be male $(40.7 \%)$, reside in an urban area $(45.3 \%)$, be over 65 years old (58.8\%), have no formal schooling $(52.2 \%)$ or be a government employee (41.9\%). Shown in Table 1 are the adjusted predictors for smokers in the three quit-stages. Respondents who were aged 45-64 years were over 2.5 times more likely to make smoking quit attempts in the next 12 months compared to those aged $\geq 65$ years $(\mathrm{OR}=2.907$; 95\% CI: $0.776-2.993)$.

Table 1. Predictors of stages of quit intention among current Nigerian smokers

\begin{tabular}{|c|c|c|c|c|c|c|c|c|c|}
\hline \multirow[t]{3}{*}{ Variables } & \multicolumn{3}{|c|}{$\begin{array}{l}\text { Precontemplation stage } \\
\text { (n-82850 1) }\end{array}$} & \multicolumn{3}{|c|}{$\begin{array}{l}\text { Contemplation stage } \\
\qquad(\text { n } 2595 \text { 16) }\end{array}$} & \multicolumn{3}{|c|}{ Preparation stage } \\
\hline & \multirow[t]{2}{*}{ IOR } & \multicolumn{2}{|c|}{$95^{\circ} \% \mathrm{CI}$} & \multirow[t]{2}{*}{ AOR } & \multicolumn{2}{|c|}{$95 \% \mathrm{CI}$} & \multirow[t]{2}{*}{ AOR } & \multicolumn{2}{|c|}{$95 \%$ CI } \\
\hline & & Lower & Upper & & Lower & Upper & & Lower & Upper \\
\hline \multicolumn{10}{|l|}{ Gender } \\
\hline Male & 0.14 & 0.07 & $0.14^{*}$ & 1.1 & 0.045 & 1.89 & 1.0 & 0.05 & $0.84^{*}$ \\
\hline Female & 1 & & & 1 & & & 1 & & \\
\hline \multicolumn{10}{|l|}{ Age (years) } \\
\hline 15-24 (young people) & 5.5 & 1.81 & $5.72^{*}$ & 1.6 & 1.35 & $1.67^{*}$ & 1.049 & 1.007 & $1.732^{*}$ \\
\hline 25-44 (young adults) & 2.4 & 1.26 & $4.57^{*}$ & 2.1 & 1.56 & $2.89^{*}$ & 1.0 & 1.0 & $4.67^{*}$ \\
\hline 45-64 (middle-aged) & 0.9 & 0.37 & 1.33 & 2.9 & 1.78 & $2.99^{*}$ & 1.0 & 0.53 & $0.99^{*}$ \\
\hline$\geq 65$ (elderly) & 1 & & & 1 & & & 1 & & \\
\hline \multicolumn{10}{|l|}{ Place of residence } \\
\hline Rural & 0.7 & 0.47 & $0.96^{*}$ & 0.9 & 1.54 & $4.95^{*}$ & 0.45 & 0.28 & 1.29 \\
\hline Urban & 1 & & & 1 & & & 1 & & \\
\hline
\end{tabular}


Table 1. Continued

\begin{tabular}{|c|c|c|c|c|c|c|c|c|c|}
\hline \multirow[t]{3}{*}{ Variables } & \multicolumn{3}{|c|}{$\begin{array}{l}\text { Precontemplation stage } \\
\text { (n-82850 1) }\end{array}$} & \multicolumn{3}{|c|}{$\begin{array}{l}\text { Contemplation stage } \\
\text { (n } 259516)\end{array}$} & \multicolumn{3}{|c|}{ Preparation stage } \\
\hline & \multirow[t]{2}{*}{ AOR } & \multicolumn{2}{|c|}{$95 \% \mathrm{CI}$} & \multirow[t]{2}{*}{ AOR } & \multicolumn{2}{|c|}{$95 \% \mathrm{CI}$} & \multirow[t]{2}{*}{ AOR } & \multicolumn{2}{|c|}{$95^{\circ} \% \mathrm{CI}$} \\
\hline & & Lower & Upper & & Lower & Upper & & Lower & Upper \\
\hline \multicolumn{10}{|l|}{ Educational status } \\
\hline No formal education & 0.5 & 0.24 & $0.99^{*}$ & 0.6 & 0.58 & $0.99^{*}$ & 0.5 & 0.25 & $0.84^{*}$ \\
\hline Primary education & 0.6 & 0.35 & $0.76^{*}$ & 1.0 & 0.92 & $1.00^{*}$ & 0.6 & 0.39 & $0.93^{*}$ \\
\hline Secondary education & 0.9 & 0.62 & 1.55 & 1.5 & 1.34 & $3.27^{*}$ & 1.0 & 0.77 & 1.97 \\
\hline Tertiary education & 1 & & & 1 & & & 1 & & \\
\hline \multicolumn{10}{|l|}{ Wealth index } \\
\hline Poor & 1.5 & 0.85 & 1.72 & 0.9 & 0.07 & 1.09 & 0.6 & 0.54 & 1.85 \\
\hline Middle & 0.7 & 0.57 & 1.37 & 0.8 & 0.19 & 1.41 & 0.6 & 0.33 & 1.14 \\
\hline Rich & 1.3 & 0.68 & 1.89 & 0.6 & 0.29 & 2.17 & 0.9 & 0.70 & 1.23 \\
\hline Richest & 1.7 & 0.81 & 2.52 & 0.5 & 0.48 & 3.89 & 0.6 & 0.45 & 2.06 \\
\hline Poorest & 1 & & & 1 & & & 1 & & \\
\hline \multicolumn{10}{|l|}{ Marital Status } \\
\hline Not currently married & 1.2 & 0.99 & 1.32 & 0.3 & 0.13 & 1.95 & 0.6 & 0.34 & 1.11 \\
\hline Currently married & 1 & & & 1 & & & 1 & & \\
\hline \multicolumn{10}{|c|}{ Exposure to health warning } \\
\hline Yes & 1.5 & 0.66 & $0.94^{*}$ & 0.5 & 0.24 & $0.99^{*}$ & 1.02 & 0.47 & $0.96^{*}$ \\
\hline No & 1 & & & 1 & & & 1 & & \\
\hline \multicolumn{10}{|c|}{ Had seen anti-tobacco message } \\
\hline Yes & 0.5 & 0.86 & $0.92^{*}$ & 0.75 & 0.495 & 3.65 & 0.8 & 0.49 & 3.66 \\
\hline No & 1 & & & & & & 1 & & \\
\hline
\end{tabular}

Respondents with no formal education were about $60 \%$ less likely to make smoking quit attempts in the next 12 months than those with tertiary education (OR=0.662; 95\% CI: 0.587-0.994). Interestingly, respondents who had seen health warnings on cigarette packs were less likely to make smoking quit attempts in the next 12 months compared to those who did not see them ( $\mathrm{OR}=0.533 ; 95 \% \mathrm{CI}$ : $0.242-0.988$ ). Male respondents were less likely to contemplate quitting someday compared to females ( OR $=0.143 ; 95 \%$ CI: 0.070-0.140). Likewise, respondents who were aged 15-24 years were about 5 times more likely to contemplate quitting smoking someday compared to those aged $\geq 65$ years ( $\mathrm{OR}=5.497$; 95\% CI: 1.807-2.723). Respondents with no formal education were $50 \%$ less likely to make smoking quit attempts someday than those with tertiary education ( $\mathrm{OR}=0.513$; 95\% CI: 0.243-0.990). Unemployed respondents were about 2.5 times more likely to contemplate quitting the habit someday compared to the government employees $(\mathrm{OR}=2.223$; 95\% CI: 2.122-2.329).

\section{DISCUSSION}

This study used the TTM construct to describe the predictors of quit attempts among current smokers in Nigeria. Most smokers record smoking quit intentions and multiple quit attempts. The multiple quit attempts highlight the difficulty most smokers have with accomplishing successful cessation as well as the importance of characterising individuals who at least attempt to quit, since they may be more likely to benefit from smoking cessation programs. The transtheoretical model helps by classifying smokers based on the stage of quitting, so targeted interventions can be provided to enhance quit rates.

There were more smokers in precontemplation stage than in contemplation and preparation stages. A study conducted among indigenous Australians who were smokers also reported that the majority 
of smokers were in the precontemplation stage $\mathrm{e}^{23}$. However, this was in discordance with results from analysis of secondary data from the Korean National Health and Nutrition examination survey, where most smokers were in contemplation stage. However, in the studies cited above, the stage with the least respondents was the preparation stage, implying that many current smokers do not have intentions to quit. In many cases, quit intentions may be influenced by serious issues such as health concerns, family members' disapproval or stricter tobacco control policies in the country, as documented in this study. For smokers in precontemplation, there is a need to assess their awareness and risk perception of the harms of smoking. Moreover, more of the smokers resided in rural areas than urban areas. More smokers residing in rural areas contrasts to the study by Palipudi et al. ${ }^{24}$ in 13 countries, where more smokers were in urban areas. The higher percentage of smokers in rural areas may be due to their perception of tobacco being harmless and use in traditional ceremonies ${ }^{10}$. There are different potential reasons for geographic differences in smoking prevalence in Nigeria. Some of these reasons include: religion, culture and tradition, social norms, varying socioeconomic status of the residents, the influence of media, and the role of the tobacco industry.

Although many of the smokers were male, there were few female smokers buttressing the fact that women are also smoking. From the 2012 GATS, 5.6\% Nigerian adults aged $\geq 15$ years currently used tobacco products: $10.0 \%$ men and $1.1 \%$ women. In all, $3.9 \%$ of adults $(7.3 \%$ of men and $0.4 \%$ of women) currently smoked tobacco, and $3.7 \%$ of adults $(7.2 \%$ of men and $0.3 \%$ of women) currently smoked cigarettes at the time in Nigeria. Most smokers being male may be because smoking among women is still not totally acceptable in Nigerian culture, despite urbanization.

Respondents who were single were less interested in quitting the smoking habit within the next 12 months compared to married respondents. Those who are married may consider quitting either due to pressure from their spouses or even their children. Also, more young people were in precontemplation stage. Youth generally are curious and mostly have no health concerns, so they are unlikely to be seriously considering quitting. Young people were less likely to be in preparation stage, perhaps because young people are curious, less likely to fully contemplate their choices, and subject to peer pressure ${ }^{25}$, therefore, preventing smoking initiation is a key intervention for the young. However, middle-aged people have more responsibilities and are more likely to be contemplative, accounting for why there were more middle-aged people in preparation stage.

Many of these smokers were also working-class age and more than half were literate. However, majority of those literate people had completed only primary school. Among male smokers who resided in rural areas, those who had completed tertiary education constituted the lowest percentage. Those smokers who have tertiary education have, most likely, relocated to the urban areas. Fewer smokers in rural areas were contemplating quitting. Smokers in rural areas can easily access cigarette sticks, which are affordable and available as single sticks ${ }^{25}$. Also, those in higher wealth quintiles had less quit intentions, which contrasts with the findings of Matthews et al. ${ }^{26}$ and Santiago et al. ${ }^{27}$. The association with socioeconomic status may be so, as those in the higher wealth quintiles may be social smokers who readily have access to quality healthcare. The rich can also easily afford tobacco and this may account for why they are less likely to quit smoking. While the poor may need to consider food or healthcare costs, which are mostly out of pocket, over smoking.

For those who had tried to quit smoking, they were able to quit for different durations. Their different quit durations may indicate that smokers may make multiple quit attempts before they achieve abstinence or relapse. The durations also indicate that different interventions will be required in addressing smokers in different categories. Smokers in Nigeria had used a few different methods to aid quitting. It was instructive to note that no one had used a quitline, few had used pharmacotherapy, and others used non-conventional methods. The importance of support for quitting was corroborated by Fiore et al. ${ }^{28}$ who documented the benefits of telephone help and pharmacologic interventions to aid smoking quits.

Exposure to anti-tobacco media messages was associated with increase in quit attempts among smokers in contemplation and precontemplation stages. The importance of anti-tobacco media messages is corroborated by Durkin et al. ${ }^{29}$ and 
Glynn et al. ${ }^{30}$. The consistent deployment of these messages via various channels will continue to provide support for quitting. While some smokers genuinely see smoking as a habit that has no adverse consequence, these messages will enlighten them. For those who have no quit intentions or unsuccessful quits, these anti- tobacco messages may give the motivation to try.

Surprisingly, increased knowledge about the harmful effects of tobacco was negatively associated with initiating quit attempts. Research has shown that knowledge does not necessarily translate to action. This finding is corroborated by studies from Balmford et al. ${ }^{25}$ and Adeyey et al. ${ }^{31}$. In addition, many, though aware of the harmful effects, have no quit intentions, such as healthcare workers who smoke tobacco. The lack of immediate adverse consequence and the addictive nature of nicotine may be responsible for knowledge without commensurate action.

\section{Strengths and limitations}

The findings are generalizable to Nigeria, however, more recent national level data from another survey such as GATS are required to compare with these findings and address gaps, which include novel tobacco products in the country and quitlines that are being developed. Furthermore, as the data were collected in 2012, they may not reflect the current status of tobacco use in Nigeria.

\section{CONCLUSIONS}

This study assessed the overall prevalence of quit intentions among smokers in Nigeria, as well as among men and women, with the higher quit intentions among men. The study also showed the social factors associated with smoking quit intentions in smokers across the country. Most smokers in Nigeria are in the precontemplation stage, suggesting that they are not considering quitting, and efforts should be targeted not just at preventing initiation, but also encouraging quitting. Also, a new survey is needed to evaluate the current tobacco control efforts. Increased access to quit support through trained professionals and pharmacotherapy are crucial for moving forward. To this extent, efforts to assist smoking quit attempts in Nigeria using targeted interventions should be put in place by the government, including quitlines, treatment support, and capacity building across socioeconomic and geopolitical divides, as well as the generation of national-level surveillance data on tobacco control.

\section{REFERENCES}

1. World Health Organization. WHO Report on the Global Tobacco Epidemic, 2008: The MPOWER package. Geneva, Switzerland: World Health Organisation; 2008. https://www.who.int/tobacco/mpower/mpower_report_ full_2008.pdf. Accessed October 15, 2019.

2. Ezzati M, Henley SJ, Lopez AD, Thun MJ. Role of smoking in global and regional cancer epidemiology: current patterns and data needs. Int J Cancer. 2005;116(6):963971. doi:10.1002/ijc.21100

3. Bunn WB, Stave GM, Downs KE, Alvir JM, Dirani R. Effect of Smoking Status on Productivity Loss. J Occup Environ Med. 2006;48(10):1099-1108. doi:10.1097/01.jom.0000243406.08419.74

4. Oluwole OI. Influence of Marketing on Tobacco Consumption Behavior in Rural and Urban Areas of the Southwestern Region of Nigeria. Irvine, CA: Universal Publishers; 2008.

5. Esson KM, Leeder SR, WHO Tobacco Free Initiative. The Millennium Development Goals and tobacco control : an opportunity for global partnership / Katharine M. Esson, Stephen R. Leeder. Geneva, Switzerland: World Health Organization; 2004.

6. Centers for Disease Control and Prevention. Quitting smoking among adults--United States, 2001-2010. MMWR Morb Mortal Wkly Rep. 2011;60(44):1513-1519. PMID:22071589.

7. United Nations Development Programme, World Health Organization. Tobacco Control Governance in Sub- Saharan Africa. https://www.undp.org/content/ undp/en/home/librarypage/hiv-aids/tobacco-controlgovernance-in-sub-saharan-africa.html. Published April 7, 2016. Accessed October 15, 2019.

8. Critchley JA, Capewell S. Mortality risk reduction associated with smoking cessation in patients with coronary heart disease: a systematic review. JAMA. 2003;290(1):86-97. doi:10.1001/jama.290.1.86

9. Diemert LM, Bondy SJ, Brown KS, Manske S. Young adult smoking cessation: predictors of quit attempts and abstinence. Am J Public Health. 2013;103(3):449-453. doi:10.2105/AJPH.2012.300878

10. Ebirim CIC, Amadi AN, Abanobi OC, Iloh GUP. The Prevalence of Cigarette Smoking and Knowledge of Its Health Implications among Adolescents in Owerri, South-Eastern Nigeria. Health. 2014;6(12):1532-1538. doi:10.4236/health.2014.612188

11. Egbe CO, Petersen I, Meyer-Weitz A. Community participation in tobacco control in a Nigerian setting. J Psychol Afr. 2013;23(2):311-315. doi:10.1080/14330237.2013.10820628

12. Erol S, Erdogan S. Application of a stage based 
motivational interviewing approach to adolescent smoking cessation: the Transtheoretical Modelbased study. Patient Educ Couns. 2008;72(1):42-48. doi:10.1016/j.pec.2008.01.011

13. Storr CL, Cheng H, Alonso J, et al. Smoking estimates from around the world: data from the first 17 participating countries in the World Mental Health Survey Consortium. Tob Control. 2010;19(1):65-74. doi:10.1136/tc.2009.032474

14. Sarkar BK, Arora M, Gupta VK, Reddy KS. Determinants of tobacco cessation behaviour among smokers and smokeless tobacco users in the states of Gujarat and Andhra Pradesh, India. Asian Pac J Cancer Prev. 2013;14(3):1931-1915. doi:10.7314/apjcp.2013.14.3.1931

15. Raji M, Abubakar I, Oche M, Kaoje A. Prevalence and determinants of cigarette smoking among in school adolescents in Sokoto metropolis, Northwest Nigeria. International Journal of Tropical Medicine. 2013;8(3):8186. doi:10.36478/ijtmed.2013.81.86

16. O'Loughlin J, Gervais A, Dugas E, Meshefedjian G. Milestones in the process of cessation among novice adolescent smokers. Am J Public Health. 2009;99(3):499504. doi:10.2105/AJPH.2007.128629

17. Siahpush M, Mcneill A, Borland R, Fong G. Socioeconomic variations in nicotine dependence, selfefficacy, and intention to quit across four countries: findings from the International Tobacco Control (ITC) Four Country Survey. Tob Control. 2006;15:iii71-iii75. doi:10.1136/tc.2004.008763

18. Reid JL, Hammond D, Boudreau C, Fong GT, Siahpush M; ITG Collaboration. Socioeconomic disparities in quit intentions, quit attempts, and smoking abstinence among smokers in four western countries: findings from the International Tobacco Control Four Country Survey. Nicotine Tob Res. 2010;12(Suppl 1):S20-S33. doi:10.1093/ntr/ntq051

19. Norberg M, Lundqvist G, Nilsson M, Gilljam H, Weinehall L. Changing patterns of tobacco use in a middle-aged population: the role of snus, gender, age, and education. Glob Health Action. 2011;4(1):5613. doi:10.3402/gha.v4i0.5613

20. Mardle T, Merrett S, Wright J, Percival F, Lockhart I. Real world evaluation of three models of NHS smoking cessation service in England. BMC Res Notes. 2012;5(1):9. doi:10.1186/1756-0500-5-9

21. Kaleta D, Makowiec-Dąbrowska T, DziankowskaZaborszczyk E, Fronczak A. Prevalence and sociodemographic correlates of daily cigarette smoking in Poland: results from the Global Adult Tobacco Survey (2009-2010). Int J Occup Med Environ Health. 2012;25(2):126-136. doi:10.2478/S13382-012-0016-8

22. World Health Organization. Fact sheets: noncommunicable diseases. https://www.who.int/topics/noncommunicable_ diseases/factsheets/en/. Accessed October 15, 2019.

23. Campbell S, Bohanna I, Swinbourne A, Cadet-James Y, McKeown D, McDermott R. Stages of change, smoking behaviour and readiness to quit in a large sample of indigenous Australians living in eight remote north Queensland communities. Int J Environ Res Public Health. 2013;10(4):1562-1571. doi:10.3390/ijerph10041562

24. Palipudi KM, Gupta PC, Sinha DN, et al. Social determinants of health and tobacco use in thirteen low and middle income countries: evidence from Global Adult Tobacco Survey. PLoS One. 2012;7(3):e33466. doi:10.1371/journal.pone.0033466

25. Balmford J, Borland R. What does it mean to want to quit? Drug Alcohol Rev. 2008;27(1):21-27. doi:10.1080/09595230701710829

26. Matthews KA, Gallo LC. Psychological perspectives on pathways linking socioeconomic status and physical health. Annu Rev Psychol. 2011;62:501-530. doi:10.1146/annurev.psych.031809.130711

27. Santiago CC, Wadsworth ME, Stump J. Socioeconomic status, neighborhood disadvantage, and poverty-related stress: Prospective effects on psychological syndromes among diverse low-income families. PennState. 2011;32(2):218-230. doi:10.1016/j.joep.2009.10.008

28. Fiore MC, Keller PA, Curry SJ. Health system changes to facilitate the delivery of tobacco-dependence treatment. Am J Prev Med. 2007;33(6 Suppl):S349-S356. doi:10.1016/j.amepre.2007.09.001

29. Durkin S, Brennan E, Wakefield M. Mass media campaigns to promote smoking cessation among adults: an integrative review. Tob Control. 2012;21(2):127-138. doi:10.1136/tobaccocontrol-2011-050345

30. Glynn T, Seffrin JR, Brawley OW, Grey N, Ross H. The globalization of tobacco use: 21 challenges for the 21 st century. CA Cancer J Clin. 2010;60(1):50-61. doi:10.3322/caac.20052

31. Adeyeye O. Cigarette smoking habits among senior secondary school students in Lagos, south west Nigeria. Int J Biol Med Res. 2011;2(4):1047-1050. https://www. biomedscidirect.com/journalfiles/IJBMRF2011352/ cigarette_smoking_habits_among_senior_secondary_ school_students_in_lagos_south_west_nigeria.pdf. Accessed October 15, 2019.

ACKNOWLEDGEMENTS

The authors acknowledge the GATS Nigeria data collection team who made the dataset available.

\section{CONFLICTS OF INTEREST}

The authors have completed and submitted the ICMJE Form for Disclosure of Potential Conflicts of Interest and none was reported.

\section{FUNDING}

There was no source of funding for this research.

PROVENANCE AND PEER REVIEW

Not commissioned; externally peer reviewed. 